\title{
Scutellaria baicalensis decreases ritonavir-induced nausea
}

\author{
Han Aung1,2, Sangeeta Mehendale 1,2, Wei-Tien Chang1,2, Chong-Zhi Wang1,2, \\ Jing-Tian Xie ${ }^{1,2}$ and Chun-Su Yuan*1,2,3
}

\begin{abstract}
Address: ${ }^{1}$ Tang Center for Herbal Medicine Research, Pritzker School of Medicine. The University of Chicago, IL 60637, USA, ${ }^{2}$ Departments of Anesthesia \& Critical Care. Pritzker School of Medicine. The University of Chicago, IL 60637, USA and ${ }^{3}$ Committee on Clinical Pharmacology and Pharmacogenomics. Pritzker School of Medicine. The University of Chicago, IL 60637, USA

Email: Han Aung - haung@dacc.uchicago.edu; Sangeeta Mehendale - smehendale@dacc.uchicago.edu; Wei-

Tien Chang - wchang@medicine.bsd.uchicago.edu; Chong-Zhi Wang - czwang@dacc.uchicago.edu; Jing-Tian Xie - jtxie@dacc.uchicago.edu; Chun-Su Yuan* - cyuan@airway.uchicago.edu

* Corresponding author
\end{abstract}

Published: 20 December 2005

AIDS Research and Therapy 2005, 2:12 doi:10.1186/1742-6405-2-12
Received: 15 August 2005

Accepted: 20 December 2005

This article is available from: http://www.aidsrestherapy.com/content/2/1/12

(C) 2005 Aung et al; licensee BioMed Central Ltd.

This is an Open Access article distributed under the terms of the Creative Commons Attribution License (http://creativecommons.org/licenses/by/2.0), which permits unrestricted use, distribution, and reproduction in any medium, provided the original work is properly cited.

\begin{abstract}
Background: Protease inhibitors, particularly ritonavir, causes significant gastrointestinal disturbances such as nausea, even at low doses. This ritonavir-induced nausea could be related to its oxidative stress in the gut. Alleviation of drug-induced nausea is important in effectively increasing patients' compliance and improving their quality of life. Conventional anti-emetic drugs can only partially abate the symptoms in these patients, and their cost has also been a concern. Rats respond to nausea-producing emetic stimuli by increasing consumption of non-nutritive substances like kaolin or clay, a phenomenon known as pica. In this study, we used this rat pica model to evaluate the effects of Scutellaria baicalensis, a commonly used oriental herbal medicine, on ritonavir-induced nausea.
\end{abstract}

Results: Rats treated with $20 \mathrm{mg} / \mathrm{kg}$ ritonavir significant caused increases of kaolin consumption at 24 to $48 \mathrm{hr}(P<0.0 \mathrm{I})$. Pretreatment with 0.3 and $3 \mathrm{mg} / \mathrm{kg}$ Scutellaria baicalensis extract significantly decreased ritonavir-induced kaolin intake in a dose-related manner $(P<0.0 \mathrm{I})$. Compared to vehicle treatment, the extract completely prevented ritonavir-induced kaolin consumption at dose $3 \mathrm{mg} / \mathrm{kg}$. The area under the curves (AUC) for kaolin intake from time 0 to $120 \mathrm{hr}$ for vehicle only, ritonavir only, SbE $0.3 \mathrm{mg} / \mathrm{kg}$ plus ritonavir, and SbE $3 \mathrm{mg} / \mathrm{kg}$ plus ritonavir were $27.3 \mathrm{~g} \bullet \mathrm{hr}, 146.7 \mathrm{~g} \bullet \mathrm{hr}, 123.2 \mathrm{~g} \bullet \mathrm{hr}$, and $32.7 \mathrm{~g} \bullet \mathrm{hr}$, respectively. The reduction in area under the curves of kaolin intake from time 0 to $120 \mathrm{hr}$ between ritonavir only and SbE $0.3 \mathrm{mg} / \mathrm{kg}$ plus ritonavir, ritonavir only and SbE $3 \mathrm{mg} / \mathrm{kg}$ plus ritonavir were $16.0 \%$ and $77.7 \%$, respectively.

Conclusion: Scutellaria baicalensis significantly attenuated ritonavir-induced pica, and demonstrated a potential in treating ritonavir-induced nausea.

\section{Introduction}

HIV infection/AIDS is a deadly disease that has affected over 30 million people world-wide and at least a million people in this country [1]. To achieve the treatment goal of reduction in viral loads and improved life expectancy, the treatment guidelines entail that patients be highly compliant to the drug regimens for an extended period of time $[2,3]$. However, the main obstacle that dissuades the 


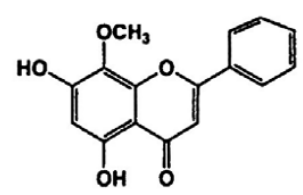

Wogonin

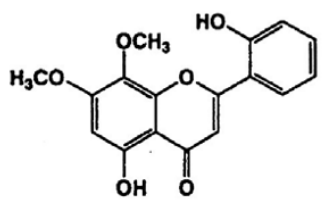

Skullcapflavone I

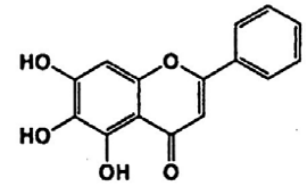

Baicalein

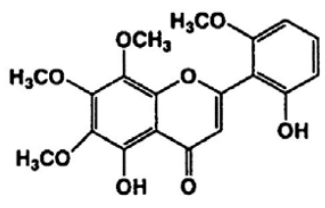

Skullcapflavone II

\section{Figure I}

Structures of four major constituents isolated from Scutellaria baicalensis roots.

patient from the goal is medication-induced side effects [2]. These side effects not only cause deterioration of the quality of life, but also have a major negative impact on compliance [4]. Nausea/vomiting is one such significant medication-related side effect that has been widely reported [5-10].

Protease inhibitor is a commonly used class of anti-HIV drugs $[11,12]$. Protease inhibitors, especially ritonavir, however, cause significant gastrointestinal disturbances, such as nausea/vomiting $[7,8,11]$. Although ritonavir can be used as a protease inhibitor by itself, it produces numerous side effects at the doses needed for an anti-viral effect, and thus it is poorly tolerated. Often ritonavir is used at a low dose to "boost" the drug levels of other protease inhibitors. Even at low doses, patients still could have ritonavir induced gastrointestinal side effects, especially nausea [12-14]. The incidence of ritonavir induced nausea/vomiting is approximately 23\%, significantly higher than other antiretroviral agents [15]. Thus, alleviation of ritonavir-induced nausea could improve patients' compliance and their quality of life. Conventional antiemetic drugs can only partially abate the symptoms in these patients, and their cost has also been a concern [16].

Rats react to nausea/vomiting stimuli by altered feeding habits, manifested as increased consumption of nonnutritive substances like kaolin (a type of clay), known as pica [17-20]. We previously demonstrated a significant anti-nausea (anti-pica) effect of anti-oxidant herbal medicines, i.e., Scutellaria baicalensis and ginseng, in cisplatininduced pica in rats $[21,22]$. It has been shown that ritonavir caused endothelial cell cytotoxicity and oxidative stress, and this oxidative stress could be a mechanism of ritonavir-induced tissue dysfunction $[23,24]$. In this study, we used a rat model to investigate the role of antioxidant herb, S. baicalensis extract (SbE) in decreasing ritonavir-induced nausea.

\section{Methods \\ Animals}

The experimental protocol was approved by the Institutional Animal Care and Use Committee (IACUC) of the University of Chicago. Male Wistar strain rats (Harlan Sprague Dawley, Indianapolis, IN), weighing between 150-300 g, were used in this study. Animals were housed in standard isolation cages $(45 \mathrm{~cm} \times 35 \mathrm{~cm} \times 25 \mathrm{~cm})$ in environmentally controlled conditions with $12 \mathrm{hr}$ light / $12 \mathrm{hr}$ dark cycle. Rats were allowed free access to water, standard laboratory rat chow (Harlan-Teklad, Madison, WI) and kaolin (see below), placed in separated containers continuously available throughout the experiment.

\section{Preparation and analysis of S. baicalensis extract (SbE)}

$S$. baicalensis was obtained from a single batch from the Beijing Chinese Herbal Medicine Company. Voucher specimen was deposited in our laboratory at the Tang Center for Herbal Medicine Research, University of Chicago. The herbal sample was tested by Applied Consumer Services (Hialeah Gardens, FL), and it has been confirmed that the sample is free from contaminants such as microorganisms, pesticide residues, and toxic elements.

The root of S. baicalensis was soaked in cold water for $2 \mathrm{hr}$, and then cut into small pieces (less than $2 \mathrm{~mm}$ ). These pieces were treated with hot water (approximately $95^{\circ} \mathrm{C}$ ) for $1 \mathrm{hr}$. The filtrate obtained following the hot water treatment was evaporated under vacuum and lyophilized. During the experiment, the dried powder was dissolved in balanced salt solution (BSS), and centrifuged for $5 \mathrm{~min}$ $(1,200 \mathrm{rpm})$. The supernatant was used.

The extract was analyzed by liquid chromatography/mass spectrometry (LC/MS, Hitachi M1000, Hitachi Denshi, Ltd., Japan) with Atmospheric Pressure Chemical Ionization interface. The extract was dissolved in deionized water at a concentration of $1 \mathrm{mg} / \mathrm{ml}$. The mobile phase was $14 \mathrm{mM}$ ammonium acetate in acetonitrite (v/v:1/99) and flow rate was $0.8 \mathrm{ml} / \mathrm{min}$. The sample $(150 \mu \mathrm{l}$ solution) was injected. The system was calibrated with flavopiridol. The extract contained the following flavones: wogon $(51.5 \%)$, baicalein $(35.6 \%)$, skullcapflavone I (4.8\%), and skullcapflavone II (8.3\%) (Figure 1) [25].

\section{Kaolin preparation}

Kaolin was prepared based on the method described previously [21]. Briefly, pharmacological grade kaolin (or hydrated aluminum silicate; Fisher, Fair Lawn, NJ) and acacia (or Gum Arabic; Fisher, Fair Lawn, NJ) were mixed 


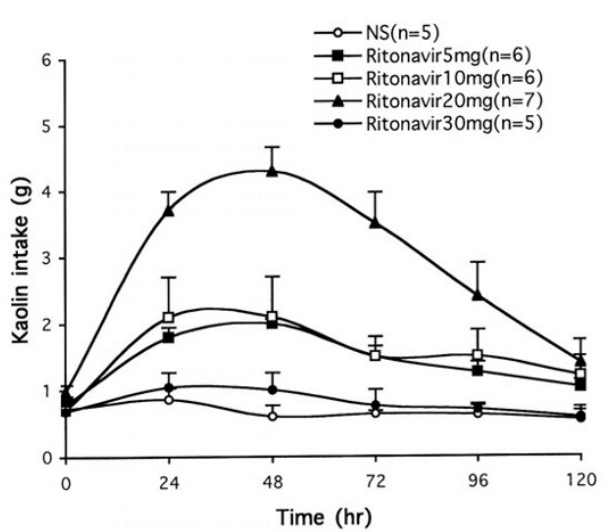

Figure 2

Effect of ritonavir $(\mathrm{mg} / \mathrm{kg})$ on kaolin intake in rats. Ritonavir doses at 5,10 and $20 \mathrm{mg} / \mathrm{kg}$ induced significant increases of kaolin intake at 24 and $48 \mathrm{hr}(P<0.0 \mathrm{I})$, while $30 \mathrm{mg} / \mathrm{kg}$ did not further increase kaolin intake. NS = normal saline.

using a 99:1 ratio. Distilled water was used to form a thick paste of this mixture. The paste was rolled and cut into pieces that resembled regular rat chow pellets. The pellets were dried at room temperature for $72 \mathrm{hr}$.

\section{Experimental protocol}

Rats placed in individual cages were allowed access to both regular food and kaolin during the 3-day adaptation period prior to study period. Rats then received ritonavir in the morning on 2 consecutive days ( 0 and 24 hrs) by oral gavage [26-28]. SbE and baicalein pretreatments were administered intraperitoneally [21], 30 min prior to each ritonavir administration. Rats were observed immediately and at $2 \mathrm{hr}$ to ensure that animals are not distressed and they are comfortable.

During the experiment, kaolin and food pellets was weighed to the nearest $0.1 \mathrm{~g}$ and replaced in the containers every morning at the same time after collecting the remaining kaolin and food from the previous day. Kaolin and food intake was measured every $24 \mathrm{hr}$ for 5 days.

The animals did not demonstrate any signs of adverse effects such as restlessness or respiratory distress following test administrations.

\section{Statistical analysis}

Data were analyzed using a two-way analysis of variance (ANOVA) with group and time as the two factors. Statistical significance was considered at $P<0.05$.

\section{Results}

Rats treated with vehicle (normal saline) only consumed less than $1 \mathrm{~g}$ /day of kaolin during the consecutive 5 days $(0,24,48,72,96,120 \mathrm{hr})$, indicating that saline does not obviously induce pica (Figure 2). Figure 2 also showed effects of ritonavir on kaolin intake. Ritonavir doses at 5 , 10 and $20 \mathrm{mg} / \mathrm{kg}$ significant caused increases of kaolin consumption at 24 to $48 \mathrm{hr}$ in a dose-related manner $(P<$ $0.01)$. Increasing ritonavir dose to $30 \mathrm{mg} / \mathrm{kg}$ did not further increase kaolin intake, suggesting toxic effect at higher ritonavir dose. This possible toxic effect was supported by the fact that at $30 \mathrm{mg} / \mathrm{kg}$, ritonavir significantly reduced food intake at 24 to $48 \mathrm{hr}(P<0.05$; Figure 3$)$. Based on these results, we selected $20 \mathrm{mg} / \mathrm{kg}$ ritonavir dose for evaluation of herbal effects on the drug-induced pica.

Figure 4 demonstrated that pretreatment with SbE significantly decreased ritonavir-induced kaolin intake in a dose-related manner $(P<0.01)$. Compared to vehicle treatment, SbE at dose $3 \mathrm{mg} / \mathrm{kg}$ completely prevented ritonavir-induced kaolin consumption. The area under the curves (AUC) for kaolin intake from time 0 to $120 \mathrm{hr}$ for vehicle only, ritonavir only, SbE $0.3 \mathrm{mg} / \mathrm{kg}$ plus ritonavir, and SbE $3 \mathrm{mg} / \mathrm{kg}$ plus ritonavir were $27.3 \mathrm{~g} \bullet \mathrm{hr}, 146.7$ $\mathrm{g} \bullet \mathrm{hr}, 123.2 \mathrm{~g} \bullet \mathrm{hr}$, and $32.7 \mathrm{~g} \bullet \mathrm{hr}$, respectively. The reduction in AUC of kaolin intake between ritonavir only and SbE $0.3 \mathrm{mg} / \mathrm{kg}$ plus ritonavir, ritonavir only and SbE 3 $\mathrm{mg} / \mathrm{kg}$ plus ritonavir were $16.0 \%$ and $77.7 \%$, respectively. Food intake was not affected significantly in all these groups.

In addition, when SbE $3 \mathrm{mg} / \mathrm{kg}$ was administered alone, the extract did not affect kaolin consumption and food intake.

\section{Discussion}

Typically, AIDS patients are treated with combinations of different drug groups to achieve the therapeutic goals of reduced viral loads and improved life expectancy [1]. Potent as these drugs may be, they are certainly not free from side effects [1], and thus add a challenging dimension to the management of drug-related adverse reactions. Patient adherence to the therapeutic regimen is of vital importance, as non-adherence can result in reduced suppression of viral load and also development of drug resistance [29]. Adherence of more than or equal to $95 \%$ is required to maintain control over viral replication, but in reality, the adherence rate is often lower with most studies showing that $40-60 \%$ of patients are less than $90 \%$ adherent [3]. Apart from other causes, drug-induced side effects are greatly responsible for poor patient compliance. Frequency and severity of side effects was one of the primary barriers to adherence, with nausea/vomiting topping the list of side effects [2]. Thus, any step towards improving 


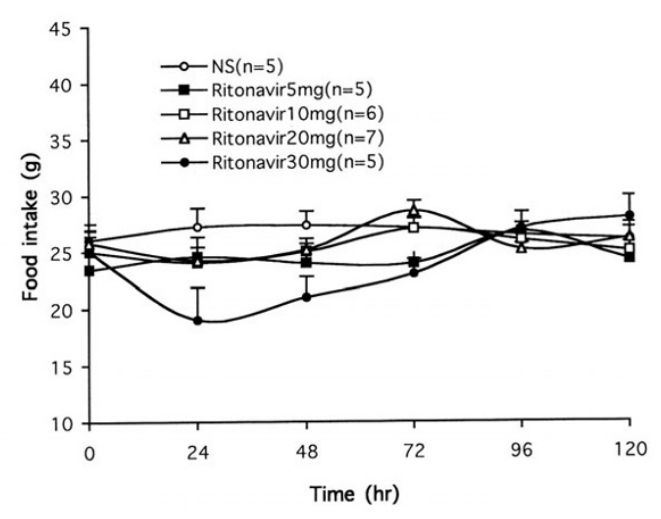

Figure 3

Effects of ritonavir $(\mathrm{mg} / \mathrm{kg})$ on food intake in rats. There was a significant reduction in food intake following $30 \mathrm{mg} / \mathrm{kg}$ ritonavir treatment at 24 and $48 \mathrm{hr}(P<0.05)$. NS $=$ normal saline.

patients' adherence to the drug regimen is vital for successful management of the disease.

The mechanism by which ritonavir causes nausea has not been investigated. Protease inhibitors cause premature cardiovascular diseases $[23,30]$. It has been shown that ritonavir induced cytotoxicity of human endothelial cells $[23,30]$. Conklin et al. [24] investigated the effects of ritonavir on vascular endothelial cell function in porcine carotid arteries. Superoxide and nitrotyrosine levels were measured. They observed that endothelium-dependent vasorelaxation was significantly reduced in ritonavirtreated vessels compared to controls. There were significant increases in basal and NADPH-stimulated superoxide production in vessel rings treated with ritonavir compared to control vessels. Dihydroethidium staining and nitrotyrosine staining were also elevated in endothelial cells of ritonavir-treated vessels, indicating increased superoxide production and increased oxidative stress, respectively, in ritonavir-treated vessels compared to controls. Their data demonstrated that increased oxidative stress could be a mechanism of ritonavir-induced cellular dysfunction.

In addition to ritonavir, nausea/vomiting is also associated with a number of other commonly prescribed drugs in AIDS pharmacotherapy [31,32]. A combination antiretroviral therapy is advocated for initial treatment of established AIDS cases [1], and this multi-pharmacy increases the likelihood of emesis. Additionally, AIDSrelated CNS disorders, gastroparesis, autonomic neuropathy and secondary infections can further aggravate druginduced emesis [33]. Thus, anti-emetic use may have a

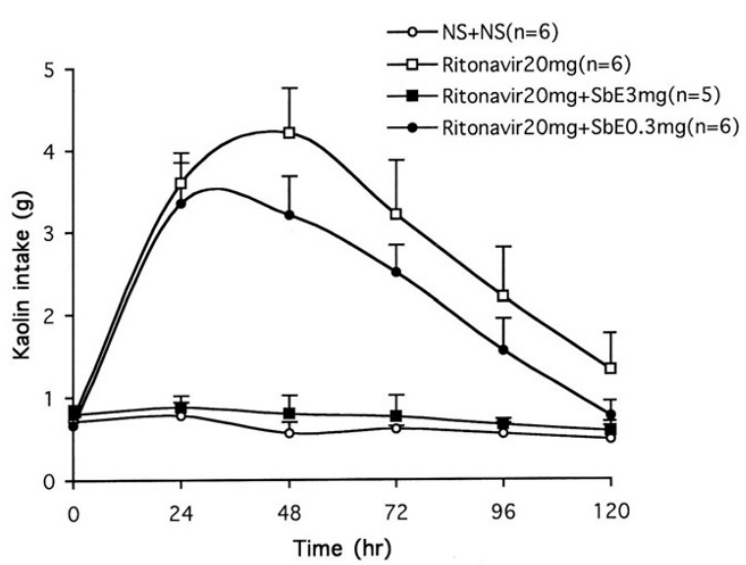

Figure 4

Effects of pretreatment with Scutellaria baicalensis extract $(\mathrm{SbE}, \mathrm{mg} / \mathrm{kg})$ on kaolin intake induced by ritonavir in rats. Increased kaolin intake induced by ritonavir $(\mathrm{mg} / \mathrm{kg}$ ) was decreased with SbE pretreatment in a dose-related manner $(P<0.0 \mathrm{I})$. NS $=$ normal saline.

wider scope in the management of AIDS patients, beyond ritonavir-induced nausea.

S. baicalensis is a widely used herb in traditional medical systems of China and Japan [34,35]. The dried root has been used clinically for allergies, inflammatory diseases, hyperlipidemia, and arteriosclerosis [34]. We previously observed that SbE attenuated cisplatin-induced emesis in rats. [34]. The major constituents in SbE are flavonoids, a group of polyhydroxy phenols [36]. These flavonoids, such as baicalein (Figure 1), possess anti-oxidant and other effects, which could also potentially be used to boost immune responses in HIV patients [37].

Several in vivo and in vitro studies have demonstrated the anti-oxidant capabilities of SbE. Kimuya et al. [36] and Kimura et al. [34] reported that liver homogenates of rats who were orally administered SbE, baicalein, and wogonin were resistant to lipid peroxidation. Gabrielska et al. [38] showed that an extract of SbE reduced liposomal lipid peroxidation. In a similar study, Gao et al. [39] observed that baicalein administration inhibited iron-dependent lipid peroxidation in rat liver microsomes. Subsequently, Gao et al. [40] showed that baicalein prevented cell death in fibroblasts damaged by $\mathrm{H}_{2} \mathrm{O}_{2}$, tetra-butyl hydroperoxide, and superoxide anions. Hamada et al. investigated in vitro radical scavenging effect of baicalein, and quantified superoxide and hydroxyl radical-scavenging effect by electron spin resonance spectrometry [41]. They reported that in a hypoxanthinexanthine system, baicalein strongly reduced superoxide radicals. Our laboratory has reported that SbE dose- 
dependently attenuated effects of reactive oxygen species (ROS) in cardiomyocytes [25].

Ritonavir is known to induce nausea in significant number of AIDS patients $[7,8,12,14]$ but has not been studied in an animal model. In this study, we observed that SbE attenuated kaolin intake or pica in ritonavirtreated rats. Our data support the hypothesis that ritonavir-induced emesis is related to its oxidative stress in the gut, and anti-oxidant herbs may have a therapeutic potential in ritonavir-induced emesis in AIDS patients.

An advantage of botanical therapies is the reduction of healthcare cost. With expensive anti-AIDS therapy, efficacious herbal products will bring down the cost of care, while providing the patient with relief from drug-induced side effects and improving their quality of life. AIDS patients are known to use herbal products more often than the general populace $[1,42]$, and evidence-based herbal therapies can offer them with a practical alternative. Thus, systematic herbal evaluation, including conducting controlled clinical trials, is important in offering options to conventional pharmacological treatment [43].

\section{Acknowledgements}

This work was supported in part by NIH grants AT002I76 and AT002445.

\section{References}

I. Sande MA, Volberding PA: The Medical Management of AIDS. 6th edition. Philadelphia, W.B. Saunders \& Co.; 1999.

2. Proctor VE, Tesfa A, Tompkins DC: Barriers to adherence to highly active antiretroviral therapy as expressed by people living with HIVIAIDS. AIDS Patient Care STDS 1999, I3:535-544.

3. Bartlett JA: Addressing the challenges of adherence. J Acquir Immune Defic Syndr 2002, 29 Suppl I:S2-10.

4. Carr A: Improvement of the study, analysis, and reporting of adverse events associated with antiretroviral therapy. Lancet 2002, 360:8I-85.

5. Hamilton JD, Hartigan PM, Simberkoff MS, Day PL, Diamond GR, Dickinson GM, Drusano GL, Egorin MJ, George WL, Gordin FM, et al.: A controlled trial of early versus late treatment with zidovudine in symptomatic human immunodeficiency virus infection. Results of the Veterans Affairs Cooperative Study. $N$ Engl J Med 1992, 326:437-443.

6. Spruance SL, Pavia AT, Mellors JW, Murphy R, Gathe JJ, Stool E, Jemsek JG, Dellamonica P, Cross A, Dunkle L: Clinical efficacy of monotherapy with stavudine compared with zidovudine in HIV. infected, zidovudine-experienced patients. A randomized, double-blind, controlled trial. Bristol-Myers Squibb Stavudine/019 Study Group. Ann Intern Med 1997, I 26:355-363.

7. Lichterfeld M, Nischalke HD, Bergmann F, Wiesel W, Rieke A, Theisen A, Fatkenheuer G, Oette M, Carls H, Fenske S, Nadler M, Knechten $\mathrm{H}$, Wasmuth JC, Rockstroh JK: Long-term efficacy and safety of ritonavir/indinavir at $400 / 400 \mathrm{mg}$ twice a day in combination with two nucleoside reverse transcriptase inhibitors as first line antiretroviral therapy. HIV Med 2002, 3:37-43.

8. Lalezari JP, Dejesus E, Northfelt DW, Richmond G, Wolfe P, Haubrich R, Henry D, Powderly W, Becker S, Thompson M, Valentine F, Wright D, Carlson M, Riddler S, Haas FF, DeMasi R, Sista PR, Salgo $M$, Delehanty J: A controlled Phase II trial assessing three doses of enfuvirtide (T-20) in combination with abacavir, amprenavir, ritonavir and efavirenz in non-nucleoside reverse transcriptase inhibitor-naive HIV-infected adults. Antivir Ther 2003, 8:279-287.

9. Gartland M: AVANTI 3: a randomized, double-blind trial to compare the efficacy and safety of lamivudine plus zidovu- dine versus lamivudine plus zidovudine plus nelfinavir in HIV-I-infected antiretroviral-naive patients. Antivir Ther 200I, 6:127-134.

10. Gelmon K, Montaner JS, Fanning M, Smith JR, Falutz J, Tsoukas C, Gill J, Wells G, O'Shaughnessy M, Wainberg M, et al.: Nature, time course and dose dependence of zidovudine-related side effects: results from the Multicenter Canadian Azidothymidine Trial. Aids 1989, 3:555-561.

II. Elperin A, Sax P: A patient's guide to protease inhibitors. AIDS Clin Care 1996, 8:83-84.

12. Mangum EM, Graham KK: Lopinavir-Ritonavir: a new protease inhibitor. Pharmacotherapy 2001, $21: 1352-1363$.

13. Greenblatt DJ, von Moltke LL, Harmatz JS, Fogelman SM, Chen G, Graf JA, Mertzanis P, Byron S, Culm KE, Granda BW, Daily JP, Shader RI: Short-term exposure to low-dose ritonavir impairs clearance and enhances adverse effects of trazodone. J Clin Pharma$\mathrm{col} 2003,43: 414-422$.

14. Nadler JP, Gathe JC, Pollard RB, Richmond GJ, Liao Q, Griffith S, Tracey Lancaster C, Hernandez JE, Pappa KA: Twice-daily amprenavir $1200 \mathrm{mg}$ versus amprenavir $600 \mathrm{mg} /$ ritonavir $100 \mathrm{mg}$, in combination with at least 2 other antiretroviral drugs, in HIV-I-infected patients. BMC Infect Dis 2003, 3: 10 .

15. Barlett JG: HIV:Current diagnosis, management, and treatment options. In HIV Disease Management Guide , PDR; 2004:101-122.

16. Meyer M: Palliative care and AIDS: 2--Gastrointestinal symptoms. Int J STD AIDS 1999, 10:495-505; quiz 506-7.

17. Mitchell D, Wells C, Hoch N, Lind K, Woods SC, Mitchell LK: Poison induced pica in rats. Physiol Behav 1976, 17:69|-697.

18. Takeda N, Hasegawa S, Morita M, Matsunaga T: Pica in rats is analogous to emesis: an animal model in emesis research. Pharmacol Biochem Behav 1993, 45:817-821.

19. Takeda N, Hasegawa S, Morita M, Horii A, Uno A, Yamatodani A, Matsunaga T: Neuropharmacological mechanisms of emesis. I. Effects of antiemetic drugs on motion- and apomorphineinduced pica in rats. Methods Find Exp Clin Pharmacol 1995, 17:589-590.

20. Takeda N, Hasegawa S, Morita M, Horii A, Uno A, Yamatodani A, Matsunaga T: Neuropharmacological mechanisms of emesis. II. Effects of antiemetic drugs on cisplatin-induced pica in rats. Methods Find Exp Clin Pharmacol 1995, 17:647-652.

21. Aung HH, Dey L, Mehendale S, Xie JT, Wu JA, Yuan CS: Scutellaria baicalensis extract decreases cisplatin-induced pica in rats. Cancer Chemother Pharmacol 2003, 52:453-458.

22. Aung HH, Mehendale SR, Xie JT, Moss J, Yuan CS: Methylnaltrexone prevents morphine-induced kaolin intake in the rat. Life Sci 2004, 74:2685-269l.

23. Zhong DS, Lu XH, Conklin BS, Lin PH, Lumsden AB, Yao Q, Chen C: HIV protease inhibitor ritonavir induces cytotoxicity of human endothelial cells. Arterioscler Thromb Vasc Biol 2002, 22: I560-I566.

24. Conklin BS, Fu W, Lin PH, Lumsden AB, Yao Q, Chen C: HIV protease inhibitor ritonavir decreases endothelium-dependent vasorelaxation and increases superoxide in porcine arteries. Cardiovasc Res 2004, 63:168-175.

25. Shao ZH, Li CQ, Vanden Hoek TL, Becker LB, Schumacker PT, Wu JA, Attele AS, Yuan CS: Extract from Scutellaria baicalensis Georgi attenuates oxidant stress in cardiomyocytes. J Mol Cell Cardiol 1999, 3 I ( I 0): I885- I895.

26. Denissen JF, Grabowski BA, Johnson MK, Buko AM, Kempf DJ, Thomas SB, Surber BW: Metabolism and disposition of the HIV-I protease inhibitor ritonavir (ABT-538) in rats, dogs, and humans. Drug Metab Dispos 1997, 25:489-50।.

27. Shibata N, Gao W, Okamoto H, Kishida T, Iwasaki K, Yoshikawa $Y$, Takada K: Drug interactions between HIV protease inhibitors based on physiologically-based pharmacokinetic model. J Pharm Sci 2002, 91 : 680-689.

28. Yamaji H, Matsumura Y, Yoshikawa Y, Takada K: Pharmacokinetic interactions between HIV-protease inhibitors in rats. Biopharm Drug Dispos 1999, 20:24I-247.

29. Nieuwkerk PT, Sprangers MA, Burger DM, Hoetelmans RM, Hugen PW, Danner SA, van Der Ende ME, Schneider MM, Schrey G, Meenhorst PL, Sprenger HG, Kauffmann RH, Jambroes M, Chesney MA, de Wolf $F$, Lange JM: Limited patient adherence to highly active antiretroviral therapy for HIV-I infection in an observational cohort study. Arch Intern Med 200I, 161:1962-1968. 
30. Lai S, Lai H, Celentano DD, Vlahov D, Ren S, Margolick J, Lima JA, Bartlett JG: Factors associated with accelerated atherosclerosis in HIV-I-infected persons treated with protease inhibitors. AIDS Patient Care STDS 2003, 17:21 I-219.

31. Richman DD, Fischl MA, Grieco MH, Gottlieb MS, Volberding PA, Laskin OL, Leedom JM, Groopman JE, Mildvan D, Hirsch MS, et al:: The toxicity of azidothymidine (AZT) in the treatment of patients with AIDS and AIDS-related complex. A doubleblind, placebo-controlled trial. N Engl J Med 1987, 3 I7:192-197.

32. Langtry HD, Campoli-Richards DM: Zidovudine. A review of its pharmacodynamic and pharmacokinetic properties, and therapeutic efficacy. Drugs 1989, 37:408-450

33. Han P, Arnold B: The challenge of chronic AIDS-related nausea and vomiting. J Palliat Med 200I, 4:65-68.

34. Kimura YOHTTAS: Studies on Scutellaria Radix. VI. Effects of flavanone compounds on lipid peroxidation in rat liver. Chem Pharm Bull 1982, 30:1792-1795.

35. Huang KC: The Pharmacology of Chinese Herbs. Boca Raton, FL, CRC Press; 1999.

36. Kimuya Y, Kubo M, Tani T, Arichi S, Okuda H: Studies on Scutellariae Radix. IV. Effects on lipid peroxidation in rat liver. Chem Pharm Bull (Tokyo) 1981, 29:2610-26I7.

37. Wu JA, Attele AS, Zhang L, Yuan CS: Anti-HIV activity of medicinal herbs: usage and potential development. Am J Chin Med 200I, 29:69-8I.

38. Gabrielska J, Oszmianski J, Zylka R, Komorowska M: Antioxidant activity of flavones from Scutellaria baicalensis in lecithin liposomes. Z Naturforsch [C] 1997, 52:817-823.

39. Gao D, Sakurai K, Chen J, Ogiso T: Protection by baicalein against ascorbic acid-induced lipid peroxidation of rat liver microsomes. Res Commun Mol Pathol Pharmacol 1995 , 90(I):103-114.

40. Gao D, Tawa R, Masaki H, Okano Y, Sakurai H: Protective effects of baicalein against cell damage by reactive oxygen species. Chem Pharm Bull (Tokyo) 1998, 46: I383-I387.

41. Hamada H, Hiramatsu M, Edamatsu R, Mori A: Free radical scavenging action of baicalein. Arch Biochem Biophys 1993, 306(I):26I-266.

42. Duggan J, Peterson WS, Schutz M, Khuder S, Charkraborty J: Use of complementary and alternative therapies in HIV-infected patients. AIDS Patient Care STDS 200I, I5:159-167.

43. Zhan L, Yue ST, Xue YX, Attele AS, Yuan CS: Effects of qian-kunnin, a Chinese herbal medicine formulation, on HIV positive subjects: a pilot study. Am J Chin Med 2000, 28:305-3I2.

\section{Publish with Bio Med Central and every scientist can read your work free of charge}

"BioMed Central will be the most significant development for disseminating the results of biomedical research in our lifetime. "

Sir Paul Nurse, Cancer Research UK

Your research papers will be:

- available free of charge to the entire biomedical community

- peer reviewed and published immediately upon acceptance

- cited in PubMed and archived on PubMed Central

- yours - you keep the copyright
BioMedcentral 